\title{
AZ31B-H24 magnezyum alaşımının sürtünme karıștırma yöntemiyle kaynak edilebilirliğinin incelenmesi
}

\author{
Sare ÇELIK, Ali ORAL ${ }^{*}$ Alper GÜNDOĞMUŞ \\ Balıkesir Üniversitesi, Mühendislik Fakültesi, Makine Mühendisliği Bölümü- Balıkesir, Türkiye \\ Geliş Tarihi (Received Date): 25.04.2020 \\ Kabul Tarihi (Accepted Date): 17.06.2020
}

$\ddot{O} \mathbf{z}$

Magnezyum ve alaşımları, hafifliği ve yüksek spesifik mukavemeti nedeni ile endüstride kullanımı oldukça yaygın olan metal olup otomotiv ve uzay-uçak sanayilerindeki mühendislik uygulamalarında ön plana çıkmıştır. Magnezyum alaşımının yanıcı ve düşük ergime sicakliğına sahip olması bu alaşımların ergitme yöntemleriyle kaynaklı birleştirilmesinde sorunlar oluşturmaktadır. Sürtünme karıştırma kaynağı, düşük işlem sicaklığı, iyi mekanik özellikler sağlaması gibi avantajları nedeni ile magnezyum alaşımlarına uygulanabilir bir birleştirme metodudur. Çalışmada, AZ31B-H24 magnezyum alaşım levhalarının sürtünme karıştırma kaynak yöntemi ile kaynak edilebilirliği incelenmiştir. Çalışmada, sürtünme karıştırma kaynak parametreleri olarak 1000, 1400 dev/dak dönme hizları; 16, 25, 40, $50 \mathrm{~mm} /$ dak ilerleme hizlart ve 15, $20 \mathrm{~mm}$ omuz çaplarl seçilerek bu parametrelerde kaynaklama işlemi yapılmıştır. Sürtünme karıştırma kaynağı uygulanan parçaların mekanik özellik tespiti için çekme ve mikro sertlik ölçme testleri uygulanmış, mikro yapı incelemeleri için kaynakl yapının optik görüntüleri incelenmiş ve XRD analizleri yapılmıştır. Çekme deneyi sonucunda, kaynaklı bağlantıların mukavemeti ana malzemeye göre \%75,88'lik bir kaynak dayanım değeri să̆lamıştır.

Anahtar kelimeler: AZ31B-H24, sürtünme karlştırma kaynağl, mekanik özellikler, mikro yapı.

Sare ÇELİK, scelik@balikesir.edu.tr, http://orcid.org/0000-0001-8240-5447

*Ali ORAL, alioral@balikesir.edu.tr, http://orcid.org/0000-0002-9144-3821

Alper GÜNDOĞMUŞ, alpergundogmus@balikesir.edu.tr, http://orcid.org/0000-0003-3922-4354 


\title{
Investigation of weldability of AZ31b-H24 magnesium alloy by friction welding method
}

\begin{abstract}
Properties of magnesium alloy such as its flammability and low melting temperature create problems in combining these alloys by melting methods. Friction stir welding is a joining method that can be applied to magnesium alloys due to its advantages such as low operating temperature and providing good mechanical properties. In this study, the weldability of AZ31B-H24 magnesium alloy sheets by friction stir welding method were investigated. As friction stir welding parameters, rotational speeds of 1000, 1300 RPM, feed rates of 16, 25, 40, $50 \mathrm{~mm} / \mathrm{min}$, and shoulder diameter of 15,20 $\mathrm{mm}$ were selected and welding was performed based on these parameters. Tensile and microhardness measurement tests were applied to determine the mechanical properties of the parts that friction stir welding was applied, optical images of the welded structure were examined and XRD analyzes were conducted for microstructure examinations. As a result of the tensile test, it turned out that the strength of the welded joints provided a weld strength value of $\% 75.88$ compared to the main material.
\end{abstract}

Keywords: AZ31B-H24, friction stir welding, mechanical properties, micro structure.

\section{Giriș}

Magnezyum, hafifliği, yüksek özgül ısı kapasitesi ve yüksek ses absorbsiyonu nedeni ile endüstride kullanımı oldukça yaygın olan bir metaldir. Otomotiv ve uzay-uçak sanayilerindeki ağırlık tasarrufuna yönelik arayışlarda magnezyum metalinin, 1.74 $\mathrm{g} / \mathrm{cm}^{3}$ olan düşük yoğunluğu ile mühendislik uygulamaları açısından en hafif yapısal metal olarak ön plana çıktığı görülmektedir. Alüminyumdan \% 36, çelikten ise $\% 78$ oranında daha hafif olan magnezyum alaşımlarının kullanımı, her yıl yaklaşık \%15 artış göstermekte ve otomobil endüstrisinde magnezyum kullanımının 30.000 ton/y1 değerinden 130.000 ton/yıl değerine ulaştığı tespit edilmiştir. $\mathrm{Bu}$ artış, ağırlık tasarrufunun çok daha önemli olduğu uzay/uçak uygulamalarındaki potansiyeli de işaret ettiği anlaşılmıştır.

Endüstriyel uygulamalarda hafif malzeme kullanımı ile birlikte yapılan araştırmalar magnezyum alaşımlarının kaynaklı bağlantıları ve özelliklerinin incelenmesi üzerine odaklanmıştır. Magnezyum alaşımının yanıcı özelliğe sahip olması bu alaşımların ergitme yöntemleriyle kaynaklı birleştirilmesinde sorunlar teşkil etmektedir. Sürtünme karıştırma kaynağı (SKK), düşük işlem sıcaklığı, iyi mekanik özellikler sağlaması, zehirli gaz ve buhar oluşturmaması, kaynak sarf malzemelerine ihtiyaç duyulmaması gibi birçok avantajları olan bir yöntemdir. Bahsedilen özellikler arasındaki düşük işlem sıcaklığı, magnezyum alaşımı gibi düşük ergime sıcaklığına sahip hassas malzemelerde SKK 'nın uygulanabilir bir metot olmasını sağlamıştır. SKK'nın 1991 yılında patenti alınmış ve öncelikle alüminyum alaşımlarının kaynağı için kullanılmıştır [1-4]. Yıllar içinde; alüminyum, magnezyum, titanyum, bakır ve çelik malzemelerin birleştirilmesinde iyi kaynak kaliteleri sağlamıştır. Son zamanlarda da farklı malzeme çiftlerinin birleştirilmesi ile ilgili çalışmalar da yapılmıştır [5-8]. Farklı Magnezyum alaşımlarına sürtünme karıştırma kaynak uygulamaları yapılarak mekanik özellikler ve içyapıları üzerindeki etkileri incelenmiştir. A.Razal Rose ve arkadaşları, kaynak hızının 
AZ61A Mg alaşımının sürtünme karıştırma kaynağına etkilerini incelemişlerdir. Kaynak hızının, karıştırma bölgesinde, tane boyutu sertlik ve çekme dayanımı üzerinde büyük etkiye sahip olduğunu ifade etmişlerdir [9]. S. Rajakumar ve arkadaşları, AZ61A $\mathrm{Mg}$ alaşımını hem SKK hem de tungten inert gas kaynağı ile birleştirmişler ve mekanik özelliklerini karşılaştırmışlardır. SKK da, çekme dayanımında \%12, akma dayanımında \%18 daha iyi değerler elde etmişlerdir. Bunun nedeni olarak işlem sıcaklığının düşük olmasından dolayı $\mathrm{Al}_{12} \mathrm{Mg}_{17}$ partiküllerinin termal dengesinden kaynaklandiğını belirtmişlerdir [10]. S.Ugender ve arkadaşları, AZ31B Mg alaşımında SKK parametrelerinin mekanik özelliklere etkilerin araştırmışlardır. Deneysel çalışmanın yanında ANOVA ile Taguchi yöntemini kullanarak optimizasyon yapmışlardır. Sonuç olarak en etkili kaynak parametrelerinin sırasıyla, dönme hızı, ilerleme hızı ve takım profili olduğunu bildirmişlerdir [11]. Wenya Li ve arkadaşları, sabit omuzlu karıștırıcı uç kullanarak AZ31B Mg alaşımını farklı parametrelerle SSK uygulamışlar ve düzgün, parlak kaynak yüzeyleri elde etmişlerdir. Takım dönme hızı arttırdıkça tane boyutunun arttığını, çekme gerilmesi artarken kırılmadaki akma gerilmesi ve uzamanın azaldığını ifade etmişlerdir. 1500 dev/dak takım dönme hızında yüksek bağlantı kalitesi elde etmişlerdir [12]. Bhukya Srinivasa Naik ve diğerleri, AZ31B-H24 Mg alaşımını çeşitli bindirme konfigürasyonlarında SKK ile bindirme kaynağı ile birleştirerek artık gerilmeleri ve mekanik özelliklerini incelemişlerdir. Bu amaçla $-40{ }^{\circ} \mathrm{C}$, oda sicaklığ $1(25$ $\left.{ }^{\circ} \mathrm{C}\right)$ ve $180{ }^{\circ} \mathrm{C}$ de kesme testi uygulamışlardır. En yüksek kesme dayanımını bütün sicaklıklar için 1000 dev/dak dönüş hızı ve $20 \mathrm{~mm} / \mathrm{s}$ ilerleme hızlarında elde etmişlerdir [13]. Sevvel $\mathrm{P}$ ve Jaiganesh $\mathrm{V}$, sürtünme karıştırma bindirme kaynaklı AZ31B Mg alaşımlarında, işlem parametrelerinin mikroyapı ve mekanik özelliklere etkilerini incelemişler ve maksimum $183 \mathrm{MPa}$ çekme dayanımı, $101 \mathrm{MPa}$ akma dayanımına ulaşmışlardır [14].

Ancak otomotiv ve uçak sanayinde kullanımı yaygınlaşan AZ31B-H24 magnezyum alaşımlarında, farklı işlem parametre kombinasyonları ile sınırlı sayıda çalışma bulunmaktadır ve yüksek dayanım değerlerine ulaşılabilmesi için halen çalışmalar devam etmektedir. $\mathrm{Bu}$ çalışmanın amacı da, AZ31B-H24 magnezyum alaşımının sürtünme karıştırma kaynağı ile birleştirilmesinde kaynak probu devir sayısı, ilerleme hızı ve takım omuz çapı parametrelerinin kaynaklı bağlantılarındaki mekanik özelliklere etkilerinin incelenmesidir.

\section{Materyal ve metod}

$\mathrm{Bu}$ çalışmada, AZ31 B-H24 magnezyum alaşımının sürtünme karıştırma kaynak yöntemi ile kaynak edilebilirliği araştırılmıştır. Haddeleme yöntemi ile üretilmiş ve kalınlığı 3,2 mm olan Magnezyum AZ31 B-H24 levhalar $150 \mathrm{mmx100} \mathrm{mm}$ boyutlarında hazırlanmıştır. Çalışmada kullanılan AZ31B-H24 magnezyum alaşımının kimyasal bileşimi Tablo 1 de verilmiş olup, sertliği $76 \mathrm{HV}$, maksimum çekme dayanım değeri $258 \mathrm{MPa}$, akma dayanımı $174 \mathrm{MPa}$ ve yüzde uzaması \% 15' dir.

Tablo 1. Magnezyum AZ31 B-H24 alaşımının kimyasal bileşimi

\begin{tabular}{|r|c|c|c|c|c|c|c|l|}
\hline AZ31B-H24 & $\mathrm{Al}$ & $\mathrm{Mn}$ & $\mathrm{Zn}$ & $\mathrm{Si}$ & $\mathrm{Cu}$ & $\mathrm{Ni}$ & $\mathrm{Fe}$ & Temper \\
\hline \% Ağırlık & 3.2 & 0.42 & 1.03 & 0.0190 & 0.0008 & 0.0006 & 0.0020 & $\mathrm{H} 24$ \\
\hline
\end{tabular}

SKK takımı olarak, silindirik profile sahip, DIN 1.3343 yüksek hız çeliğinden üretilmiş takım kullanılmıştır. Takım yekpare olup iki taraflı omuz ve pim profiline sahiptir. Bir 
tarafı $5 \mathrm{~mm}$ pim çapı, $15 \mathrm{~mm}$ omuz çapı, diğer tarafı $5 \mathrm{~mm}$ pim çapı, $20 \mathrm{~mm}$ omuz çapında silindirik pim profiline sahiptir. Şekil 1 de kullanılan takımın teknik resmi ve görüntüsü verilmiştir. Üretimi yapılan karıştırıcı uca 1sıl işlem uygulanarak 62 HRC sertlik kazandırılmıştır. SKK işlemi için Balıkesir Üniversitesi Mühendislik Fakültesi CNC Tezgahları Laboratuvarındaki LER VQ-75 marka CNC dik freze kullanılmıştır.

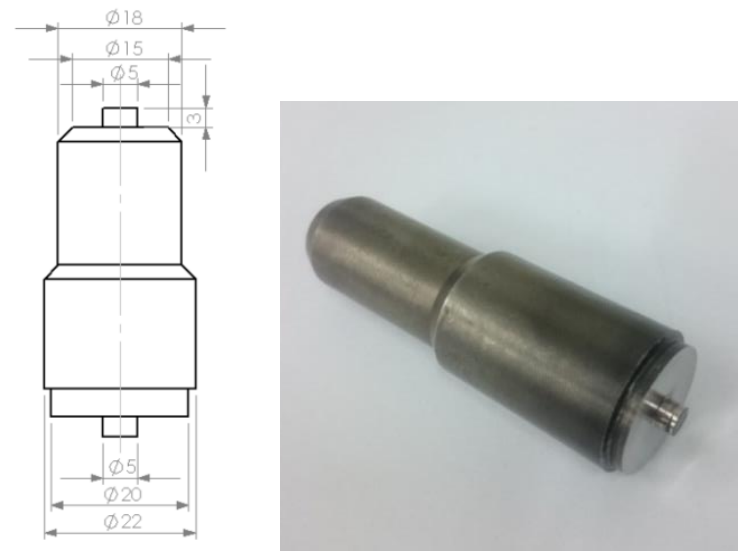

Şekil 1. Deneylerde kullanılan karıştırıcı teknik resmi ve görüntüsü.

SKK kaynağı yapılacak levhalar, CNC dik işlem merkezine iş bağlama kalıbı ile Şekil 2 de görüldüğü gibi alın yüzeyleri birbirine temas edecek şekilde tasarlanmış iş bağlama kalıbından yararlanılmıştır. Parçalar, giyotin makas ile kesildikten sonra SKK işlemi sırasında temas edecek olan levhaların alın yüzeylerinin tam temas sağlanması için frezelenmiştir. Parametrelerin belirlenmesinde öncelikli olarak literatür araştırması yapılmış olup, daha sonra yapılan ön denemeler sonucunda kaynak parametreleri Tablo 2 de verildiği gibi belirlenmiştir. SKK, malzemenin haddeleme yönüne dik olarak gerçekleştirilmiştir. Yeterli ısının sağlanabilmesi için omuz çapı ile orantılı olarak kaynak başlangıcında bekleme süresi uygulanmıştır. Literatüre uygun olarak omuz çap1 pim uzunluğundan $0.1 \mathrm{~mm}$ fazla malzemeye batırılmıştır.

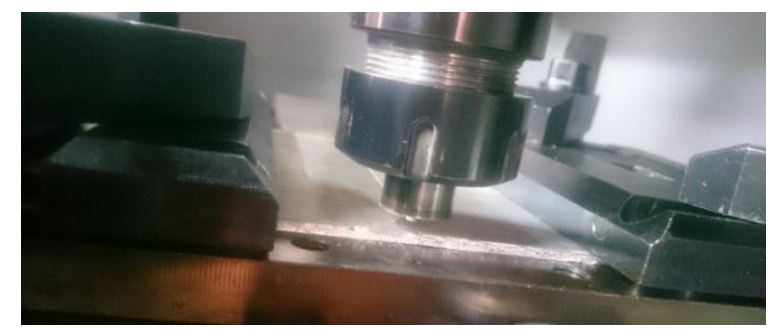

Şekil 2. Levhaların bağlama kalıbı ile tezgaha sabitlenmesi.

Tablo 2. Sürtünme karıştırma kaynak parametreleri.

\begin{tabular}{|c|c|c|c|}
\hline Deney No & $\begin{array}{c}\text { Devir Say1S1 } \\
(\text { dev/dak })\end{array}$ & $\begin{array}{c}\text { İlerleme Hiz1 } \\
(\mathrm{mm} / \mathrm{dak})\end{array}$ & $\begin{array}{c}\text { Takım Omuz } \\
\text { Çap1 }(\mathrm{mm})\end{array}$ \\
\hline $\mathbf{1}$ & 1000 & 25 & 15 \\
\hline $\mathbf{2}$ & 1400 & 40 & 15 \\
\hline $\mathbf{3}$ & 1400 & 50 & 15 \\
\hline $\mathbf{4}$ & 1000 & 40 & 20 \\
\hline $\mathbf{5}$ & 1000 & 50 & 20 \\
\hline $\mathbf{6}$ & 1000 & 15 & 15 \\
\hline $\mathbf{7}$ & 1400 & 25 & 20 \\
\hline $\mathbf{8}$ & 1400 & 15 & 20 \\
\hline
\end{tabular}


SKK işleminden sonra kaynaklı numunelerin makro kontrolleri gözle yapılmıştır. Elde edilen kaynaklı parçalar, TS EN ISO 6892-1 standardına uygun olarak 3'er adet çekme test numuneleri ve mikro yapı incelemeleri için numuneler çıkartılmıştır. Kaynak yapılan numunelerin kaynak başlangıcı ve bitiminden itibaren ilk ve son $25 \mathrm{~mm}$ 'lik kısımları incelemeye dâhil edilmemiştir. Çekme testleri, "Zwick / Roell” marka çekme test cihazında, "Balıkesir Üniversitesi Bilim ve Teknoloji Uygulama ve Araştırma Merkezi" laboratuvarında gerçekleştirilmiştir. Çekme cihazının kapasitesi $10 \mathrm{kN}$ olup ve deneyler $2 \mathrm{~mm} /$ dak çekme hızı ile yapılmıştır. Kaynak yapılan levhaların sertlik ölçümleri için Metkon MH-6 Vickers mikro sertlik ölçüm cihazı kullanılmıştır. Sertlik ölçümleri için kaynak kesitine dik olacak şekilde alınan numunelerin orta ekseninde mikrosertlik ölçümleri yapılarak, bölgeler arasındaki sertlik değişimi incelenmiştir. Sertlik ölçümlerinde, $2 \mathrm{~kg}$ yük, $1 \mathrm{~mm}$ aralıklarla $10 \mathrm{~s}$ uygulanmıştır.

SKK yapılan levhaların kaynak bölgesindeki meydana gelen yapı değişimi ve kaynağa etki eden parametrelerin yapıdaki etkisini belirlemek amaciyla mikroyapi incelemesi gerçekleştirilmiştir. Bu amaçla; kaynak yönüne dik olarak kaynak bölgesinden $25 \times 10$ mm boyutlarında alınan numuneler, bakalite alınarak sırası ile 180-1200 gridlik zımpara ile parlatma zımparalama işlemi yapılmıştır. Sonrasında ise 3 ve 1 mikrometrelik tane boyutuna sahip alümina solisyon ile parlatılmıştır. Parlatma işlemine tabi tutulan bu numuneler 4,2 gr picric asit $10 \mathrm{ml} \mathrm{su}, 70 \mathrm{ml}$ Etanol, $10 \mathrm{ml}$ asetik asit çözeltisi hazırlanarak dağlanmıştır. Optik mikroskop incelemeleri LEICA Metal Mikroskobu ile yapılmıştır. Sıcaklığın etkisi ile oluşabilecek intermetalik fazların belirlenebilmesi amacı ile Dokuz Eylül Üniversitesi Mühendislik Fakültesi laboratuvarında XRD analizleri gerçekleştirilmiştir.

\section{Deneysel sonuçlar ve tartışma}

SKK yapılmış AZ31B-H24 numunelere makro seviyede görsel olarak bakıldığında genel olarak oldukça düzgün birleştirmelerin olduğu görülmüştür. Şekil 3 'de kaynak dikişinin farklı parametrelerdeki kaynaklı parçaların makro görüntüleri verilmiştir. Görüntüler incelendiğinde kaynak parametrelerine bağlı olarak kaynak yüzey kalitelerinin değiştiği görülmektedir. Kaynak probu devir sayısı ve ilerlemeye bağlı olarak kaynaklı yüzeylerde boşluk ve çatlakların olduğu, hatalı bölgelerin ortaya çıktığı söylenebilir.

Farklı deney parametreleri ile SKK yapılmış numunelerden standartlara göre hazırlanmış olan çekme numuneleri Şekil 4 de görülmektedir. Deneyler sonrası ortalama çekme dayanım sonuçları Tablo 3 de, çekme testi sonrası kopan kaynaklı parçalar ise Şekil 5 'te verilmiştir. 
ÇELIK S., ORAL A., GÜNDOĞMUŞ A.

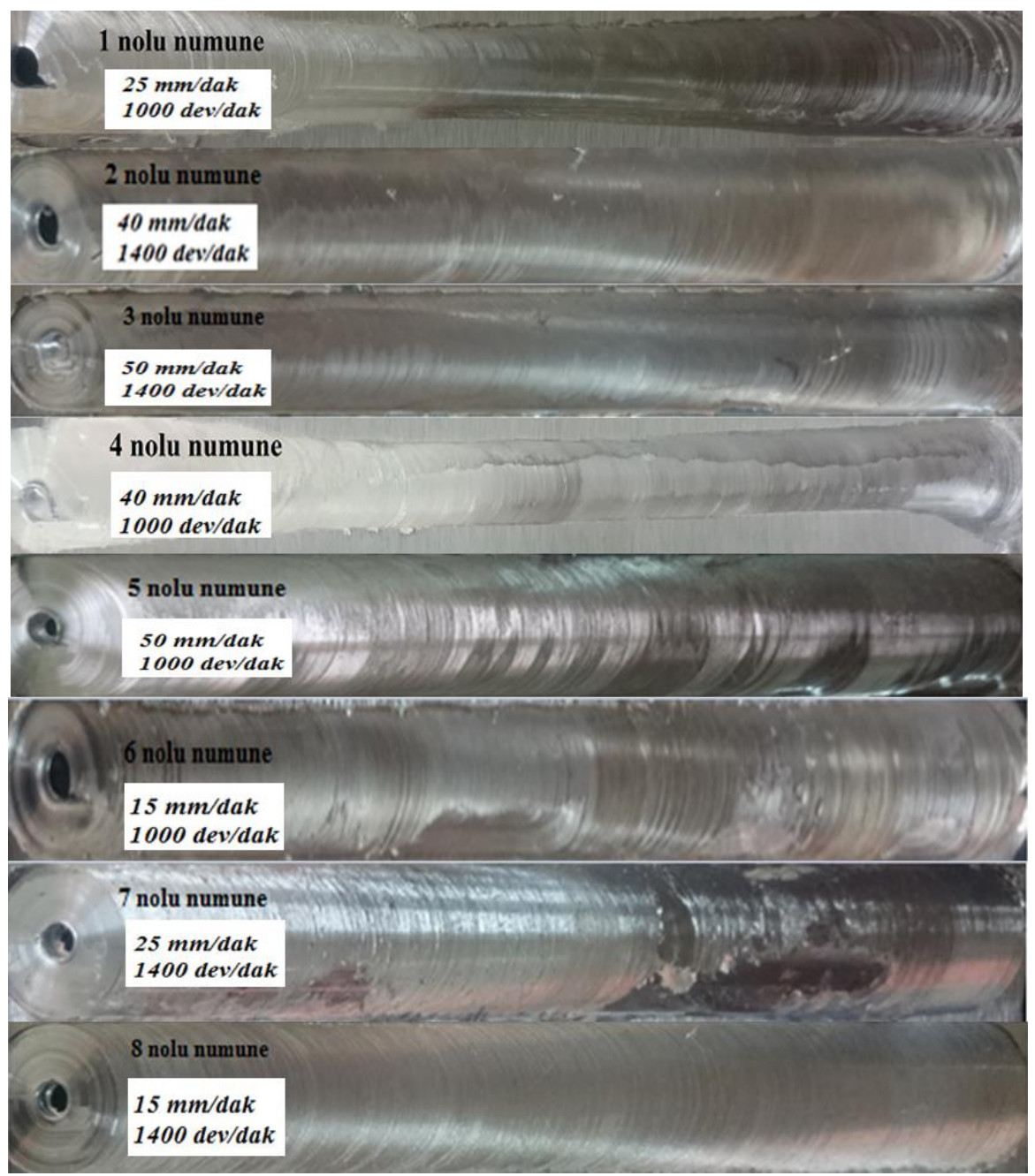

Şekil 3. Farklı parametrelerdeki kaynaklı parçaların makro görüntüsü.

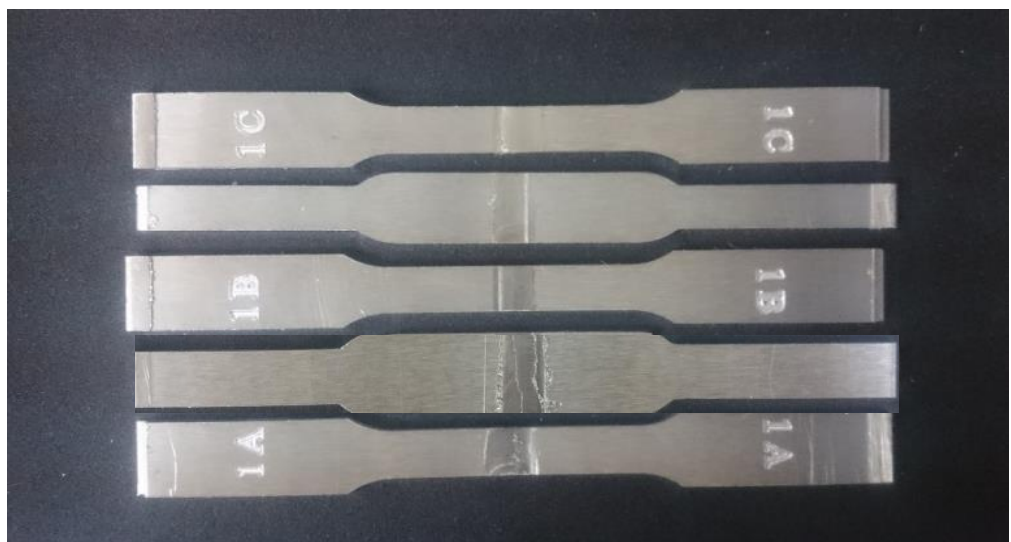

Şekil 4. Kaynaklı parçadan çıkartılan test numuneleri.

Çekme testi sonuçları incelendiğinde, en yüksek 195,77 MPa çekme dayanım değeri $1400 \mathrm{~d} / \mathrm{d}$ devir sayısı, $50 \mathrm{~mm} /$ dak ilerleme hızı ve $15 \mathrm{~mm}$ lik omuz çapı ile 3 nolu numunede; en düşük çekme dayanım değerinin ise $116,86 \mathrm{MPa}$ çekme dayanımı değeri $1000 \mathrm{~d} / \mathrm{d}$ devir sayısı, $15 \mathrm{~mm} /$ dak ilerleme hızı ve $15 \mathrm{~mm}$ lik omuz çapı ile 6 nolu numunede olduğu görülmektedir. En yüksek dayanım değeri ile ana malzemeye göre 75,88 lik kaynak performansı elde edilmiştir. Devir sayısı 1000 dev/dak dan 1400 
dev/dak ya çıktığında dayanım değeri artmıştır ancak ilerleme hızına bağlı değişimlere bakıldığında ise ilerleme hızının artması dayanım değerini düşürmüştür. Sürtünme karıştırma kaynağında devir sayısının arttırılması takım ile kaynaklanacak malzeme arasındaki sürtünmeyi arttıracağından 1sı girdisini arttırmaktadır. İlerleme hızı arttığında ise takım ile parça arasındaki temas süresi azalacağından malzemeye olan 1sı girişi azalacaktır. Dolayısıyla devir sayısı ile 1sı girdisi doğru orantılı, ilerleme hızı ile ters orantılıdır. Omuz çapının etkisine bakıldığında ise omuz çapının artması parça ile temas yüzeyini arttırdığından ısı girdisi artmaktadır. Devir sayısının ve omuz çapının birlikte fazla artması, ilerlemenin belli bir değerin altına inmesi ile gereğinden fazla 1sı girdisi nedeni ile kaynak bölgesinde sert ve gevrek yapılarından dolayı birleştirmelerin mekanik özelliklerini olumsuz yönde etkileyen intermetalik bileşiklerin oluşmasından dolayı dayanımda tekrar düşmelerin olduğu düşünülmektedir.

Tablo 3. Magnezyum AZ31B- H24 SKK yapılmış numunelerin çekme deney sonuçları.

\begin{tabular}{|c|c|c|c|c|c|c|}
\hline Numune No & $\begin{array}{c}\text { Devir } \\
\text { Say1s1 } \\
(\text { dev/dak })\end{array}$ & $\begin{array}{c}\text { İlerleme } \\
(\mathrm{mm} / \mathrm{dak})\end{array}$ & $\begin{array}{c}\text { Omuz Çap1 } \\
(\mathrm{mm})\end{array}$ & $\begin{array}{c}\text { Çekme } \\
\text { Dayan1m1 } \\
(\mathrm{MPa})\end{array}$ & $\begin{array}{c}\text { Kopma } \\
\text { Uzamas1 } \\
(\%)\end{array}$ & $\begin{array}{c}\text { Mukavemet } \\
\text { Performans1 } \\
(\%)\end{array}$ \\
\hline Ana Malzeme & - & - & -15 & 258 & 15 & - \\
\hline 1 & 1000 & 25 & 15 & 151,66 & 4 & 58,7829 \\
\hline 2 & 1400 & 40 & 15 & 177,77 & 2 & 68,9031 \\
\hline 3 & 1400 & 50 & 15 & 195,77 & 3 & 75,8798 \\
\hline 4 & 1000 & 40 & 20 & 161,77 & 1.5 & 62,7015 \\
\hline 5 & 1000 & 50 & 20 & 176,78 & 2 & 68,5193 \\
\hline 6 & 1000 & 15 & 15 & 116,86 & 1 & 45,2945 \\
\hline 7 & 1400 & 25 & 20 & 179,86 & 1 & 69,7131 \\
\hline 8 & 1400 & 15 & 20 & 189,25 & 2 & 73,3527 \\
\hline
\end{tabular}

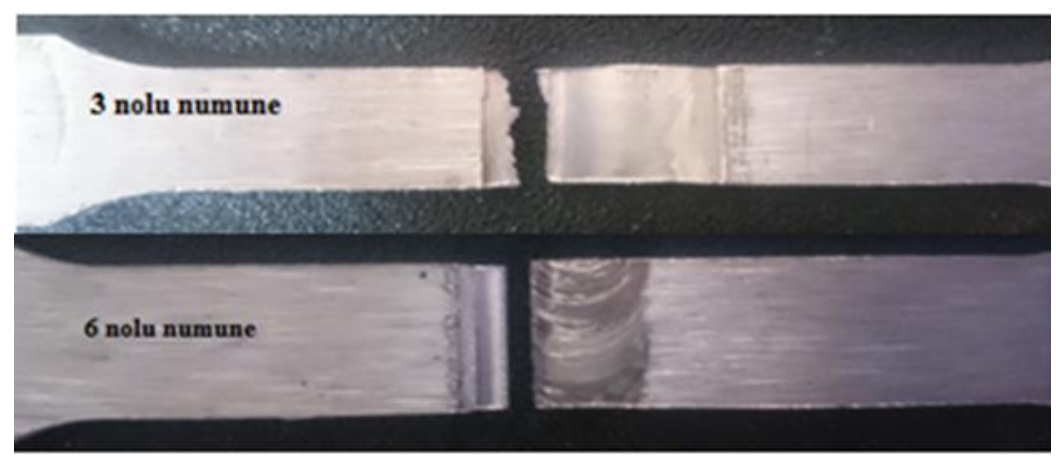

Şekil 5. 3 ve 6 nolu numunelerin kopma bölgeleri.

Çekme testleri sonrası kırılma bölgeleri incelendiğinde ise şekil 5 de görüldüğü gibi kopmalar kaynak bölgesi dışında 1sıdan etkilenen bölgede gevrek kırılma şeklinde gerçekleşmiştir. Bu bilindiği gibi magnezyumun hegzagonal kristal kafes yapısına ve çapraz kayma oluşumuna bağlıdır [15].

Kaynaklı parçaların Vickers mikro sertliği kaynağın enine kesitinin orta kısmından bir hat boyunca ölçülmüştür. Çekme testleri sonucunda en yüksek ve en düşük dayanıma sahip kaynaklı numunelerin sertlik ölçüm grafikleri Şekil 6 ve Şekil 7 'de verilmiştir. Yapılan sertlik ölçümlerinde en yüksek değerler karıştırma bölgesinden alınmış ve 3 
nolu deney numunesinin en yüksek sertlik değeri 51,92 HV ve 6 nolu deney numunesinin maksimum sertlik değeri ise 53,47 HV olarak ölçülmüştür. Ana metalin ortalama mikro sertliği $53 \mathrm{HV}$ dir. Kaynaklı bölgeden ölçülen sertlik değerleri kullanılan kaynak parametreleri ile ilişkilidir. Ancak sertlik değerlerinin kaynak parametrelerinin değişiminden pek etkilenmediği ve ana malzeme ile kaynaklı bölgede sertlik değerleri arasında önemli bir değişiklik olmadığı görülmektedir. Yüksek takım dönme hızında karıştırılan malzemenin üst yüzeyinde aşırı türbülansa ve ince taneli homojen bir karışım bölgesine neden olabileceği, bu durumunda sertlik artış1 yaratmayacağ1 söylenebilir $[8,16]$. 6 nolu numunede ilerlemenin çok düşük olmas1 nedeni ile ısı girdisi artışına bağlı olarak intermetalik bileşiklerin meydana gelmesi ve daha yüksek sertliğe sahip bölgelerin oluşabileceği düşünülmüştür.

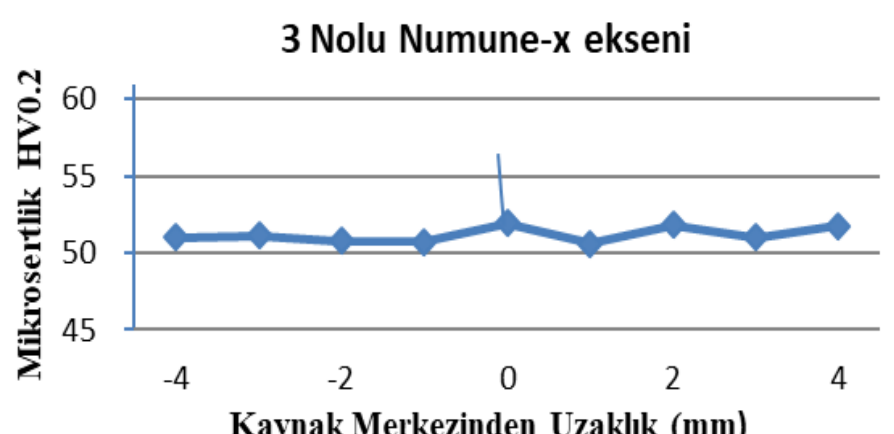

Şekil Hata! Belgede belirtilen stilde metne rastlanmadı.. 3 nolu numune mikro sertlik grafiği.

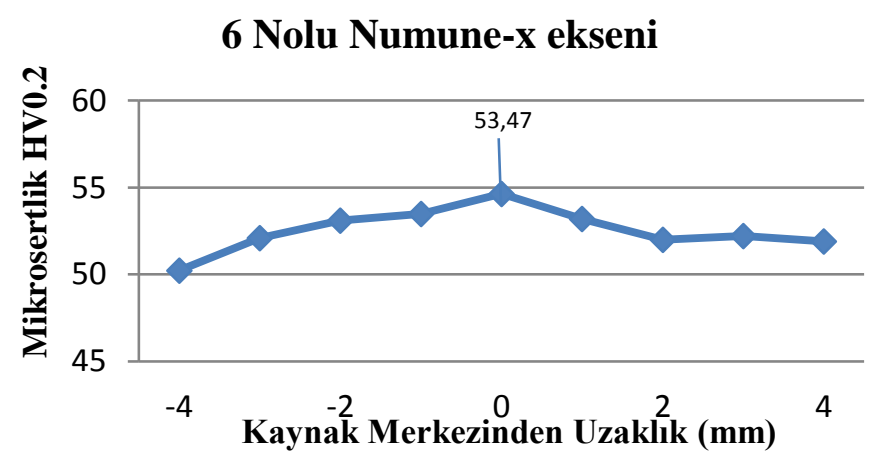

Şekil 7. 6 nolu numune mikro sertlik grafiğgi.

Sürtünme karıştırma kaynağı yapılmış AZ31B-H24 kaynaklı parçaların mikro yapıları incelenmiştir. Optik mikroskop ile mikro yapı görüntülerinin alındığı bölgeler Şekil 8'de verilmiştir. Dayanım değeri en yüksek ve en düşük olan kaynaklı parçaların numunelerinden alınan mikro yapı görüntüleri ise Şekil 9-11'de gösterilmektedir.

Kaynaklı parçaların mikro yapıları incelendiğinde, karışım (kaynak) bölgesi, 1sı etkisi altındaki bölge (ITAB) ve ana malzemeden oluşan bölgeler ayırt edilmektedir. Şekil 9 'daki 3 nolu numunenin kaynak bölgesinde, kaynak sırasında oluşan sürtünme 1sısı ve plastik deformasyon ile yeniden kristalleşmiş ince taneler yoğunlukla görülmektedir. Plastik akış kaynaklı bölgeler de düzgün tane dağılımı gözlenmiştir. Ana malzemeye yakın olan ITAB'ın mikro yapı ve mekanik özellikleri 1s1 ile değiştiği tane irileşmesi olduğu fakat herhangi bir plastik deformasyona maruz kalmadığı görülmektedir. Ayrıca 
1S1 girdisinin artmasıyla intermetalik fazların oluşabileceği düşünülmektedir. Dayanım değeri düşük olan 6 nolu numunenin mikro yapı görüntüleri incelendiğinde, kaynak bölgesinin homojen olmayan bir karışım bölgesinden oluştuğu görülmektedir. SKK yapılan numunelerin kaynaklı birleştirme bölgesinin mikro yap1 incelemesi literatür ile uyumlu olduğu görülmüştür $[8,16]$.

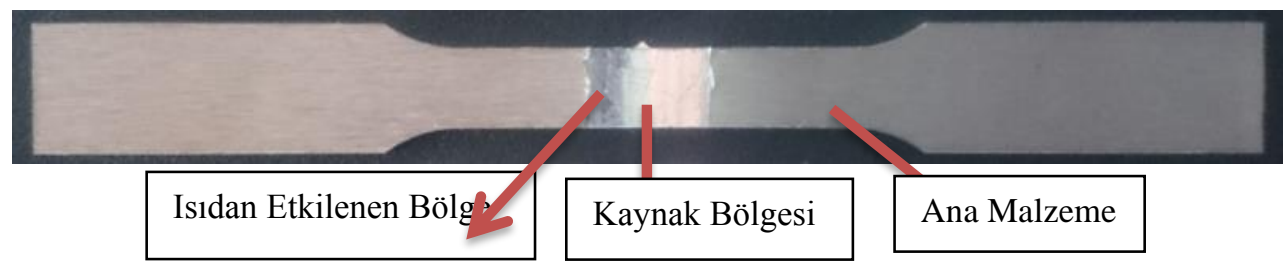

Şekil 8. Kaynaklı numuneler üzerindeki kaynak bölgeleri.

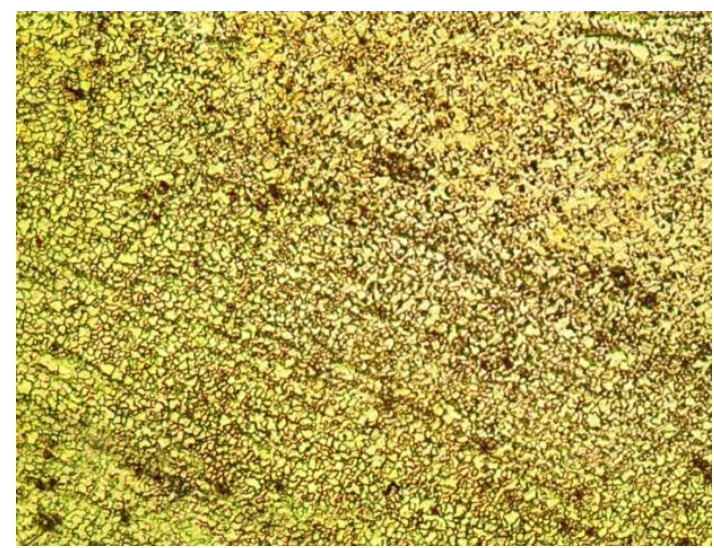

(a)

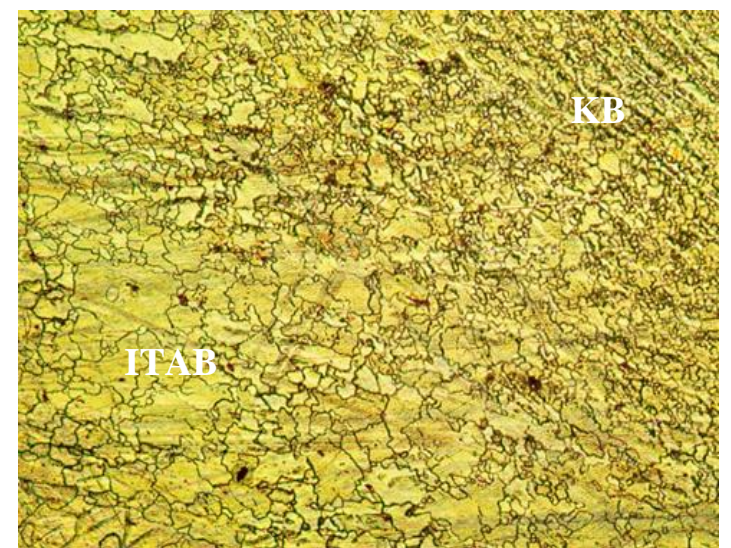

(b)

Şekil 9. 3 nolu numunenin kaynak bölgesi mikroyapısı a) kaynak bölgeleri b) 1sı etkisi altındaki bölge (100X).

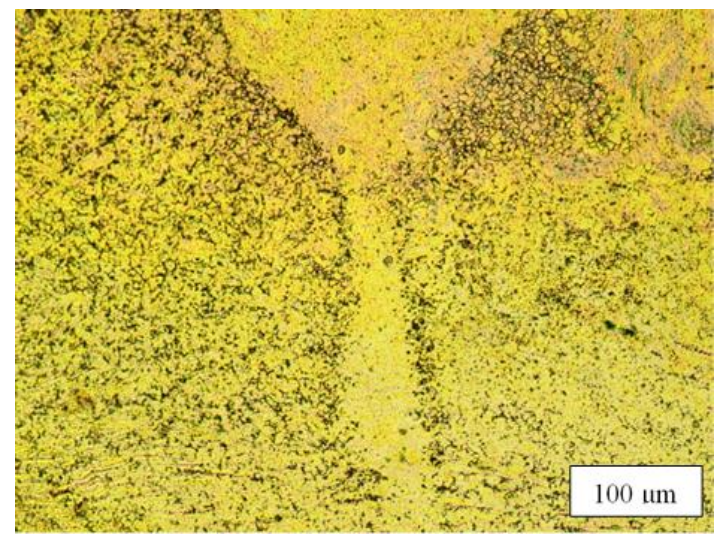

(a)

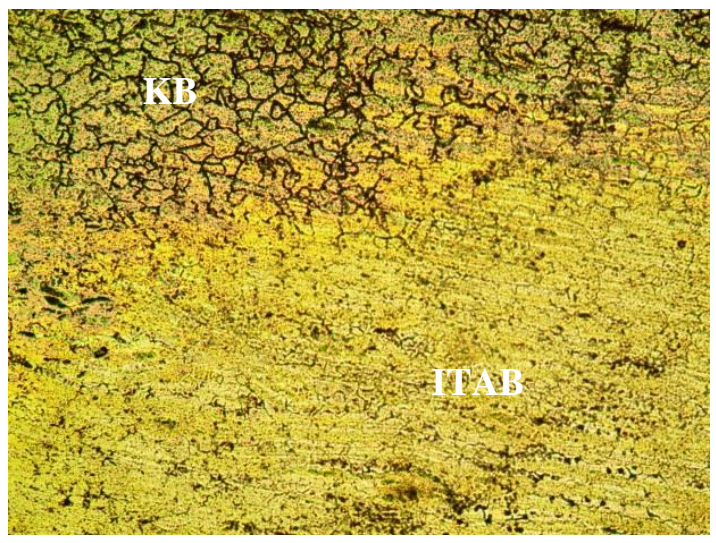

(b)

Şekil 10. 6 nolu kaynaklı numunenin mikroyapısı a) kaynak bölgeleri

b) 1s1 etkisi altındaki bölge (100X). 


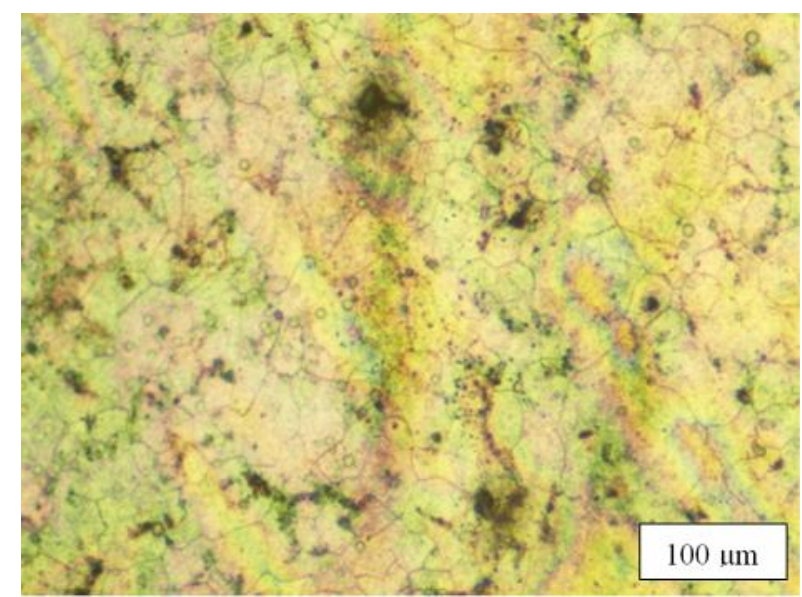

Şekil 11. Ana malzemenin (AZ1B-H24) mikroyapıs1.

Kaynak bölgesinde düşünülen intermetalik fazların belirlenmesi için yapılan XRD analiz incelemeleri ile doğrulanmıştır (Şekil 12). Görüldüğü gibi kaynaklı bölgede ( $\mathrm{Al}_{12} \mathrm{Mg}_{17}$ ve $\mathrm{Al}_{11} \mathrm{Mn}_{14}$ ) intermetalik fazları oluşmuştur. Isı girdisine bağlı olarak intermetalik fazların oluşumu ve miktarlarının malzemenin mekanik özellikleri üzerinde önemli etkilerinin olduğu bilinmektedir. Kaynaklı numunelerin dayanım değerlerinin yüksek olmasını, intermetalik fazların oluştuğu, ancak kırılganlık yaratacak boyuta ulaşmadığı şeklinde değerlendirilmiştir. Bu sonuçlar literatür ile de uyumludur $[10,17]$

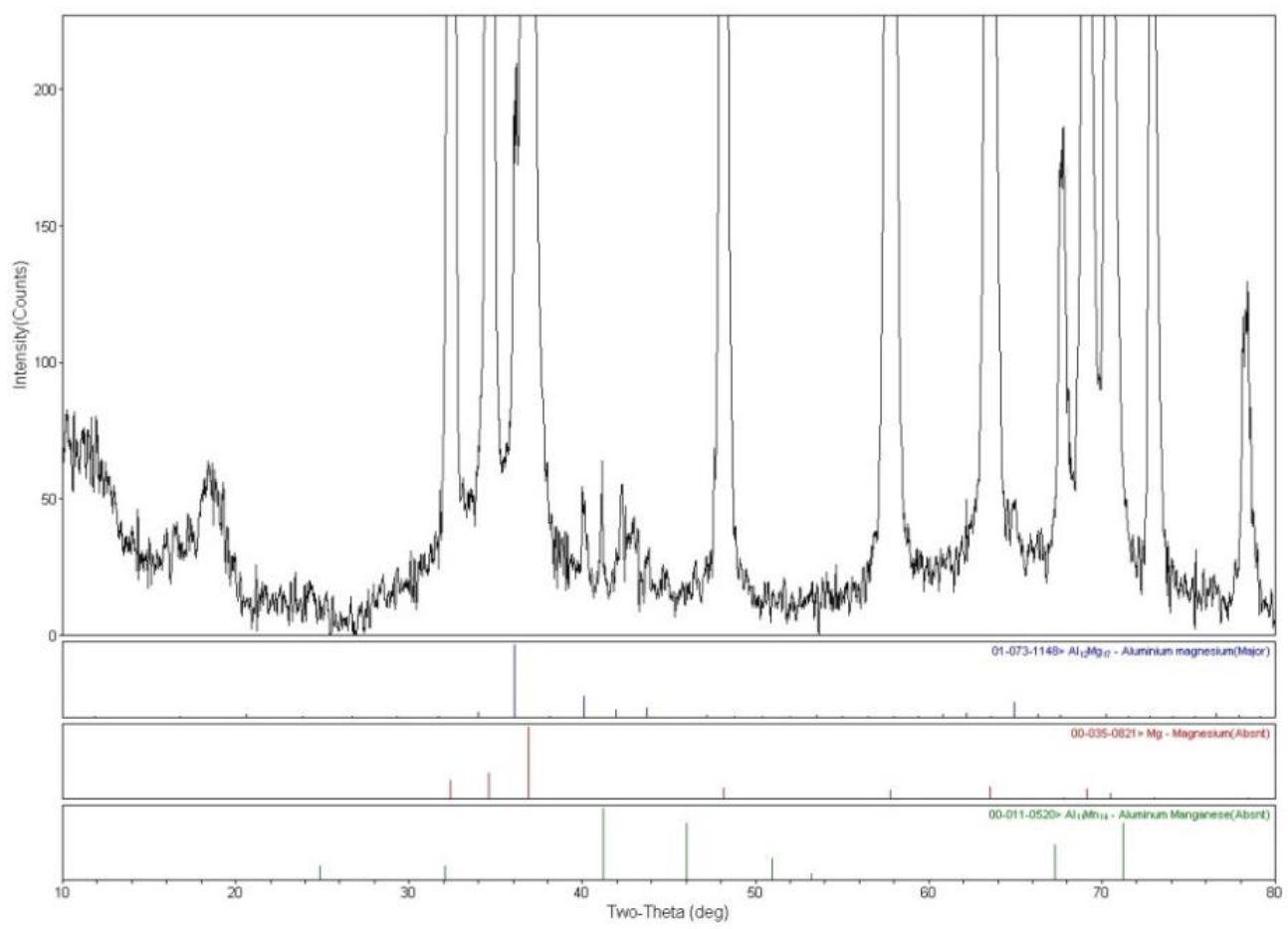

Şekil 12. Karışım bölgesine ait XRD analizi.

\section{Sonuçlar}

AZ31B-H24, Mg alaşımının sürtünme karıştırma kaynak yöntemiyle birleştirilme parametrelerinin değerlendirildiği bu çalışmada elde edilen sonuçlar aşağıda sunulmuştur. 
Ergitme kaynak yöntemleriyle oldukça zor kaynaklanan $\mathrm{Mg}$ alaşımlarından, AZ31BH24 Mg alaşımının sürtünme karıştırma kaynak yöntemi ile başarılı bir şekilde kaynaklandığı görülmüştür. Optimize edilmiş işlem parametre değerleri için mikroyap1 incelemeleri, kaynak bölgesinde ince bir şekilde bölünmüş ve tanelerin parçalanması düzgün bir şekilde gerçekleşmiştir. Plastik akış kaynaklı bölgeler de düzgün tane dağılımı gözlenmiştir. Düşük devir sayısında ve yüksek ilerleme hızlarında parçada iyi bir kaynaklanma sağlanamamıştır. Isı girdisi, devir sayısı ve omuz çap1 ile doğru, kaynak hızı ile ters orantılıdır. Isı girdisi gereğinden fazla olduğunda, intermetalik fazların oluşumu söz konusu olmaktadır. Kaynak bölgesinde sıcaklık etkisi ile oluşan $\mathrm{Al}_{12} \mathrm{Mg}_{17}$ ve $\mathrm{Al}_{11} \mathrm{Mn}_{14}$ fazların oluştuğu ve bu fazların kırılgan yapısı sebebiyle çekme dayanımının azalmasına, sertliğinin ise artmasına sebep olmuştur. Isı girdisinin azalması ise yetersiz karışım ve kaynak bölgesinde boşluklara neden olmakta bu da kaynaklı parçanın dayanımını düşürmektedir. Yapılan çalışmada, en yüksek çekme dayanım değeri $1400 \mathrm{dev} /$ dak dönme hızı, $50 \mathrm{~mm} /$ dak ilerleme hızı ve $15 \mathrm{~mm}$ lik omuz çapı ile 3 nolu numunede 195,77 MPa olarak elde edilmiştir. Ana malzemeye göre 75,88 lik bir kaynak performansı elde edilmiştir.

\section{Kaynaklar}

[1] Scialpi, A., De Filippis, L.A.C. and Cavaliere, P., Influence of shoulder geometry on microstructure and mechanical properties of friction stir welded 6082 aluminium alloy, Materials and Design, 28, 1124-1129, (2007).

[2] Elangovan, K. and Balasubramanian, V., Influences of tool pin profile and tool shoulder diameter on the formation of friction stir processing zone in AA6061 aluminium alloy, Materials and Design, 29, 362-373, (2008).

[3] Cebeci, T. ve Şahin, S., Sürtünme karıştırma kaynağı ile birleştirilen AA1050 ve AA5754-H111 alüminyum levhaların mekanik özelliklerinin incelenmesi, CBÜ Soma MYO Teknik Bilimler Dergisi, 2, 14, (2010).

[4] Heidarzadeh, A., Khodaverdizadeh, H., Mahmoudi, A. and Nazari, E., Tensile behavior of friction stir welded AA6061-T4 aluminum alloy joints, Materials and Design, 37, 166-173, (2012).

[5] Saeid, T., Abdollah-zadeh, A. and Sazgari, B., Weldability and mechanical properties of dissimilar aluminum-copper lap joints made by friction stir welding, Journal of Alloys and Compounds, 490, 652-655, (2010).

[6] Xue, P., Ni, D.R., Wang, D. B., Xiao, L. and Ma, Z.Y., Effect of friction stir welding parameters on the microstructure and mechanical properties of the dissimilar Al-Cu joints, Materials Science and Engineering A, 528, 46834689, (2011).

[7] Abdollah-Zadeh, A., Saeid, T. and Sazgari, B., Microstructural and mechanical properties of friction stir welded aluminum/copper lap joints, Journal of Alloys and Compounds, 460, 535-538, (2008).

[8] Çakır, R., AA1050/Cu Malzeme çiftinin birleştirilmesinde sürtünme karıştırma kaynak parametrelerinin mekanik ve mikroyapı özelliklerinin etkisinin incelenmesi, Doktora Tezi, Balıkesir Üniversitesi Fen Bilimleri Enstitüsü, Balıkesir, (2013).

[9] Rose, A. R., Manisekar, K. and Balasubramanian, V., Influences of welding speed on tensile properties of friction stir welded AZ61A magnesium alloy, Journal of Materials Engineering and Performance, 21, 2, 257-265, (2012). 
[10] Rajakumar, S., Balasubramanian, V. and Razalrose, A., Friction stir and pulsed current gas metal arc welding of AZ61A magnesium alloy: A comparative study, Material and Design, 49, 267-278, (2013).

[11] Ugender, S., Influence of tool pin profile and rotational speed on the formation of friction stir welding zone in AZ31 magnesium alloy, Journal of Magnesium and Alloys, 6, 2, 205-213, (2018).

[12] Li, W., Niu, PL., Yan, SR., Patel, V., Wen, Q, Improving microstructural and tensile properties of AZ31B magnesium alloy joints by stationary shoulder friction stir welding, Journal of Manufacturing Processes, 37, 159-167, (2019).

[13] Naik, B. S., Cao, X., Wanjara, P., Friedman, J. and Chen, D., Residual streses and tensile properties of friction stir welded AZ31B-H24 magnesium alloy in lap configuration, Metallurgical and Materials Transactions B, 46, 4, 1626-1637, (2015).

[14] Sevvel, P., Jaiganesh, V., Characterization of mechanical properties and microstructual analysis of friction stir welded AZ31B $\mathrm{Mg}$ alloy through optimized process parameters, Procedia Engineering, (2014).

[15] Ericsson, M., Jin, L.Z., Sandström, R., Fatigue properties of friction stir overlap welds, International Journal of Fatigue, 29, 57-68, (2007).

[16] Toktaş, A., Sürtünme karıştırma kaynak yönteminin AA 6063 alüminyum alaşımına uygulanması ve kaynak parametrelerinin malzeme iç yapısı ile mekanik özeliklerine etkisinin incelenmesi, Doktora Tezi, Balıkesir Üniversitesi Fen Bilimleri Enstitüsü, Balıkesir, (2006).

[17] Sunil, B., Reddy, R., Mounika, G.P.K., Sree, A.S.N., Navya, P., Pinneswari, P. R., Ambica, I., Babu, R.A., Amarnadh, P., Joining of AZ31 and AZ91 Mg alloys by friction stir welding, Journal of Magnesium and Alloys, 3, 330-334, (2015). 